\title{
Skoteinos ou como se ler: Adorno leitor de Hegel
}

\author{
Skoteinos or how to read: Adorno as a reader
}

\author{
Fábio Caires Correia ${ }^{1}$ \\ Oneide Perius ${ }^{2}$
}

\begin{abstract}
Resumo: Nosso objetivo neste trabalho é tentar esclarecer o mal-estar causado por algumas leituras que muitas vezes despacham a influência e a presença constante de Hegel na obra de Adorno de forma muito breve e fácil, seja a partir da perspectiva antissistêmica da filosofia adorniana, ou então, desde a perspectiva negativa que a dialética assume em seu pensamento. Nesse sentido, pretendemos expor alguns pontos fundamentais da filosofia hegeliana, em relação aos quais Adorno se coloca claramente como herdeiro. Pretendemos mostrar que o filósofo de Frankfurt pensa não somente sobre estes pontos, mas também a partir deles, i.e., superando-os.
\end{abstract}

Palavras-chave: Adorno. Hegel. Dialética. Negatividade.

\begin{abstract}
Our aim in this study is to try to clarify the uneasiness caused by some readings that often dispel Hegel's influence and ceaselessly presence in Adorno's work very briefly and easily, either from the antisystemic perspective of Adorno's philosophy, or else, from the negative perspective that the dialectic assumes in its thought. In this sense, we intend to expose some fundamental points of the hegelian philosophy, in relation to which Adorno clearly stands as heir. We intend to show that the philosopher of Frankfurt thinks not only of these points, but also since them, i.e., overcoming them. Keywords: Adorno. Hegel. Dialectic. Negativity.
\end{abstract}

Ler Hegel seria assim um procedimento experimental:

deixar surgir interpretações possíveis, propô-las, compará-las com o texto e com aquilo que já foi confiavelmente interpretado. (ADORNO, Theodor W. 1990, p. 373; 2013, p. 242).

\footnotetext{
${ }^{1}$ Doutorando em Filosofia pela PUCRS, Bolsista CAPES/PROEX. Professor substituto na Universidade Federal do Tocantins - UFT. E-mail: fabio.caires@acad.pucrs.br.

${ }^{2}$ Doutor em Filosofia pela PUCRS. Professor Adjunto de Filosofia na Universidade Federal do Tocantins - UFT. Email: oneidepe@yahoo.com.br
} 


\section{*Introdução}

Quando nos propomos revisitar e discutir a leitura adorniana do pensamento de Hegel temos que, necessariamente, justificar esta nossa escolha temática. Depois de passadas mais de cinco décadas da publicação da obra Negative Dialektik (1966) o que haveria, ainda hoje, por discutir a respeito da relação entre esses dois universos teóricos? Facilmente, sem o cuidado necessário, poderíamos reforçar o que Vladimir Safatle - de um modo muito cortês - chamou de "a posteridade filosófica" e simplesmente repetir certos chavões que foram se solidificando ao longo desses anos todos. Os exemplos mais claros a esse respeito, também referidos por Safatle (2017), seriam, i) o velho jargão habermasiano que considera a "dialética negativa adorniana, apenas como uma "prática ad hoc da negação determinada”. Em decorrência disso, Adorno (e também Horkheimer) recairiam num demasiado niilismo; e, ii) a posição adotada por Robert Pippin, de não reconhecer “a 'dialética negativa' como dialética, mas uma filosofia da finitude e uma lide para o reconhecimento de tal finitude"3 (SAFATLE, 2017, p. 227).

Nossa escolha temática, em grande parte, se justifica exatamente a partir disso. Ou seja, de um certo mal-estar em relação a essas e outras leituras que muitas vezes despacham a influência e a presença constante de Hegel na obra de Adorno de forma muito breve e fácil, seja a partir da perspectiva antissistêmica da filosofia adorniana, ou então, desde a perspectiva negativa que a dialética assume em seu pensamento. Ao tratar essas perspectivas de leitura sem o devido cuidado, corre-se o risco de colocar em Hegel, simplesmente, a etiqueta de cachorro morto (toten Hund), como Marx já alertou em certa ocasião. Ou seja, nos limitaríamos a tratar a filosofia hegeliana como se fosse uma simples perspectiva falsa que a leitura de Adorno teria a pretensão de corrigir desde sua crítica.

A linguagem de Adorno pode, por vezes, nos conduzir ao erro neste sentido. As críticas veementes ao autor da Phänomenologie des Geistes (1807) poderiam nos levar a crer, de forma equivocada, que Hegel é simplesmente um adversário ou apenas um ponto de vista inverso daquele do autor do qual ora nos ocupamos. Definitivamente não se trata disso. As

\footnotetext{
${ }^{3}$ Não é nosso interesse responder a tais conjecturas, visto que isto já foi feito em boa parte da literatura que comentam a obra do filósofo frankfurtiano. Para detalhes mais precisos cf. SAFATLE, 2017; DUARTE, 1997; 2008.
} 
críticas a Hegel remetem, no caso adorniano, a um longo processo de maturação e leitura sistemática da obra hegeliana. Segundo Adorno, "dificilmente haverá algum pensamento teórico de certo alento que, sem haver se apropriado (in sich aufgespeichert hätte) da filosofia hegeliana, pode hoje fazer justiça à experiência da consciência.” (ADORNO, 1990, p. 252; 2013, p. 74). Assim como no começo do século XX, mais especificamente em 1923, a publicação de Geschichte Und Klassenbewusstsein de György Lukács tinha como objetivo arejar o ambiente dogmático do marxismo oficial da época resgatando o seu enraizamento na potência da dialética hegeliana, também Adorno está consciente da importância de mobilizar essa dialética para compreender a dinâmica e as contradições das sociedades administradas.

Um envolvimento persistente com Hegel ensina que sua filosofia, como provavelmente em toda grande filosofia, não se pode selecionar aquilo que se gosta e rejeitar o que irrita. É essa sombria necessidade, e não algum ideal de completude, que cria a seriedade e a substancialidade da exigência sistemática de Hegel. Sua verdade se esconde no escândalo, não no plausível. Salvar Hegel, e não renová-lo, pois apenas a salvação é apropriada para ele, significa encarar sua filosofia lá onde ela é mais dolorosa; arrancar a verdade, lá onde sua inverdade é explícita (ADORNO, 1990, p. 320; 2013, p. 168-169).

Uma filosofia que simplesmente partisse de alguns princípios não questionados seria uma mera filosofia de ponto de vista. Nada mais avesso ao espírito da obra adorniana. Ler Hegel, dessa forma, antes de qualquer outra coisa, exige respeitar a dinâmica e a lógica interna de composição de sua obra. Respeitar, sobretudo, a concepção hegeliana de que toda crítica filosófica que realmente merecesse este nome tem que ser uma crítica imanente. Não se trata de criticar uma filosofia desde um outro ponto de vista. Isto torna qualquer diálogo impossível pois colocaria vis-à-vis duas lógicas distintas e construídas a partir de terminologias discordantes. Tal forma de crítica responde, muito mais, a um jogo retórico do que a uma exigência de seriedade filosófica. Crítica imanente, ao invés disso, é a verdadeira crítica filosófica na medida em que respeita um princípio hermenêutico básico, qual seja, o de compreender uma obra a partir da lógica profunda de sua composição e situar qualquer perspectiva crítica 
desde a inadequação interna, na obra estudada, entre sua lógica de composição e os resultados/análises a que esta obra chega ${ }^{4}$.

Este é, fundamentalmente, o trabalho que Adorno realiza. Ou melhor, para dizê-lo em poucas palavras, a necessária dissociação entre dialética e idealismo ou entre dialética e positividade, em última análise, seria uma exigência interna da própria filosofia hegeliana quando se leva a rigorosa lógica dessa obra às últimas consequências. "Uma crítica imanente à dialética implode o idealismo hegeliano" (ADORNO, 1973, p. 322; 2009, p. 273). O que implode, portanto, é o idealismo e não a filosofia hegeliana. Marx, sob forte influência de Feuerbach, já havia feito uma crítica desta casca mística do idealismo hegeliano desde a leitura que o levou a se apropriar do movimento e da potência dialética desta obra. Pois, "à sua maneira, Marx também visava liberar-se da natureza afirmativa da dialética hegeliana sem perder nada em determinação." (SAFATLE, 2017, p. 231). Claramente, seguindo a esteira de Marx - por consequência, a de Feuerbach -, também Adorno está mostrando a necessidade de se fazer uma crítica interna da obra hegeliana para poder continuar fazendo a análise da realidade desde a perspectiva profundamente dinâmica da dialética, sem com isso se comprometer com pontos de vista teleológicos ou totalizantes que certa leitura acrítica da obra hegeliana poderia preservar. "[É] preciso enfrentar, mesmo que inadequadamente, a exigência pela verdade de sua filosofia, ao invés de discuti-la meramente a partir de cima e, por conseguinte, a partir de baixo" (ADORNO, 1990, p.251; 2013, p. 72).

Ademais, para além desta crítica imanente que se faz extremamente necessária em certos momentos, outro elemento muito importante a se considerar na leitura que Adorno propõe da filosofia hegeliana está para além do movimento de simplesmente corrigi-la ou lhe apontar críticas necessárias. Obras filosóficas são sempre índices importantes para

\footnotetext{
${ }^{4}$ De acordo com Amaro Fleck, "existem basicamente três formas de crítica imanente: i) a crítica imanente positiva, ii) a crítica imanente positiva instrumental e, por fim, iii) a crítica imanente negativa”. Para o autor, a primeira crítica julga o existente com base no discurso legitimador, de modo que o crítico adota os valores subjacentes a tal discurso. A segunda crítica, julga o existente com base no discurso legitimador sem necessariamente concordar com ele, de maneira que faz um uso instrumental desse procedimento como uma forma de primeira aproximação. A última forma de crítica imanente, enfim, julga o existente com base no que se tornou possível, isto é, com base em uma alternativa realista e contextualizada. Adorno usa o procedimento da crítica imanente positiva num sentido instrumental, perseguindo a contradição entre o conceito e a coisa de modo a desenvolver uma crítica tanto do conceito quanto da coisa. Mas, em última instância, a sua crítica é justificada com base na crítica imanente negativa, uma vez que o sofrimento desnecessário, que já poderia estar suprimido, é o indício de que as coisas não estão bem e o que incita a crítica” (FLECK, 2016, p. 79).
} 
compreender a dinâmica concreta e as contradições do tempo histórico que as torna possíveis. Assim, por exemplo, mais do que corrigir a psicanálise freudiana, Adorno está empenhado em compreender a obra do pai da psicanálise como uma radiografia que expõe em detalhes a constituição e as contradições da sociedade burguesa. "A grandeza de Freud”, escreve ele, "consiste em que, como todos os grandes pensadores burgueses, ele deixou contradições não resolvidas e se negou a asseverar uma pretensa harmonia, quando a coisa em si era contraditória. Ele revelou o caráter hostil da realidade social.”(ADORNO, 1995, p. 40). Assim, exatamente pelo fato de Freud encontrar a objetividade social no lugar onde menos se suspeitaria que ela estivesse, ou seja, no mais íntimo do indivíduo, ele potencializa, pela sua abordagem, uma investigação acerca da reificação ou coisificação do sujeito no interior da sociedade administrada.

Hegel, nesse sentido, também é lido como uma espécie de ápice filosófico do projeto de autocertificação da modernidade. Há que tornar legível a dinâmica social concreta que torna seu pensamento inteligível e, para além disso, há que explorar a potencialidade crítica de sua obra, tendo em vista que, como bem lembrou Walter Benjamin (1994, p.224) em certa ocasião, "em todas as épocas deve-se tentar arrancar a tradição de um conformismo que está prestes a dominá-la.” Isto, no caso hegeliano, fica bastante evidente em um conjunto de leituras que utilizam sua teoria para proclamar o fim da história. É nesse sentido que pretendemos aqui ressaltar alguns pontos fundamentais da filosofia hegeliana, em relação aos quais Adorno se coloca claramente como herdeiro. Como veremos, o filósofo de Frankfurt pensa não somente sobre estes pontos que iremos expor, mas sim, a partir deles. Vejamos.

\section{Razão}

O primeiro ponto que cabe destacar, nesse sentido, é a concepção hegeliana de razão. Hegel dizia em sua famosa sentença programática da Filosofia do Direito que "o que é racional (was vernünftig ist), isto é efetivo (ist wirklich) e o que é efetivo, isto é racional” (HEGEL, 2010, p. 41). Certamente esta frase obscura deixa, num primeiro contato, bastante desconfortado o leitor. Pois, mais do que uma apologia ao existente, essa formulação remete ao fato de que a racionalidade é o movimento do real. 
Racionalidade não é simplesmente o que as pessoas pensam. Aqueles esquemas conceituais que estão meramente na cabeça de alguém não conhecem ainda a efetivação e são, portanto, uma manifestação totalmente abstrata da razão. O real, ao invés disso, é o próprio desdobramento e revelação da racionalidade. Assim, na tradição dialética hegeliana, razão quer dizer algo muito concreto que se manifesta na própria dinâmica da realidade. A própria realidade histórica, dessa maneira, com seus antagonismos constitutivos, moldou e continua moldando uma concepção de racionalidade tanto logicamente (como conceito) como ontologicamente (como uma realidade que se desdobra de acordo com a dinâmica deste conceito). Quando se fala, portanto, de racionalidade desde a tradição dialética hegeliana, não estamos falando de uma estrutura formal passível de ser deduzida de uma instância lógica fora do tempo e do espaço. Racionalidade é a própria dinâmica da realidade.

Nos parágrafos §§ 232 e 233 da Phänomenologie des Geites, Hegel define razão como consciência-de-si,

[Damit, dass das] Por que a consciência-de-si é razão, sua atitude, até agora negativa frente ao ser-outro, se converte numa atitude positiva. Até agora, só se preocupava com sua independência e sua liberdade, a fim de salvar-se e conservar-se para si mesma, às custas do mundo ou de sua própria efetividade, [já] que ambos lhe pareciam o negativo em sua essência. Mas como razão, segura de si mesma, a consciência-de-si encontrou a paz em relação a ambos; e pode suportá-los, pois está certa de si mesma como [sendo] a realidade, ou seja, está certa de que toda a efetividade não é outra coisa que ela. Seu pensar é imediatamente, ele mesmo, a efetividade; assim, comporta-se em relação a ela como idealismo. Para ela, quando assim se apreende, é como se o mundo viessea-ser pela primeira vez. Antes, não entendia o mundo: [só] o desejava e trabalhava. Retirava-se dele [recolhendo-se] a si mesma, e o abolia para si, e a si mesma [abolia] como consciência desse mundo enquanto essência e também como consciência da nulidade dele. Só agora [...] descobre o mundo como seu mundo efetivo. Agora tem interesse em permanecer nesse mundo, como antes tinha somente no seu desvanecer; pois seu subsistir se lhe torna sua própria verdade e presença. A consciência tem a certeza de que só a si experimenta no mundo. [Die Vernunft ist] A razão é a certeza da consciência de ser toda a realidade: assim enuncia o idealismo o conceito de razão (HEGEL, 1992, p.152-153).

A razão para Hegel é, neste sentido, um prosseguimento da razão crítica kantiana, porém, não se limitando ao exame das faculdades de 
conhecer. Prender-se à questão epistemológica, para Hegel, seria uma forma de limitar a própria possibilidade de conhecer. "[O] conhecimento, se quiser existir, deve ser, segundo sua ideia mesma, o conhecimento do todo" (ADORNO, 199o, p.255; 2013, p. 77). O movimento das figuras da Phänomenologie propõe um desenvolvimento imanente das formas abstratas de conhecer, tais como as primeiras figuras da consciência, ao conhecimento da realidade enquanto certeza desenvolvida pela consciência de que todas as categorias segundo as quais se estruturam a realidade objetiva são puras exteriorizações de si própria.

Hegel é capaz de pensar a partir da própria coisa, de se entregar por assim dizer de modo passivo ao seu próprio conteúdo, justamente porque a coisa, por força do sistema, é referida à sua identidade com o sujeito absoluto. As próprias coisas falam em uma filosofia que se esforça para provar que ela própria é uma e mesma coisa com elas (ADORNO, 1990, p. 255; 2013, p. 77).

Assim, quando Adorno e Horkheimer insistem tanto na importância hermenêutica do conceito de razão instrumental para compreender a dinâmica das sociedades administradas, isto aponta justamente para um processo de efetivação de um modelo de racionalidade pobre e restrito baseado simplesmente num cálculo de meios para fins que não admitem nenhuma abordagem racional. Sociedade administrada, assim, é simplesmente uma sociedade construída a partir da vigência deste modelo pobre de racionalidade que se torna canônico nas sociedades contemporâneas. A dinâmica concreta da realidade social mostra a efetivação desta racionalidade estreita. Portanto, uma racionalidade que na modernidade foi saudada como potência emancipatória ao possibilitar o acesso aos meandros das decisões políticas, por exemplo, se vê agora amputada num contexto em que a estrutura social arcaica esconde seus mecanismos constitutivos e deixa para a racionalidade unicamente a tarefa de calcular meios para a realização dos fins postos por esta estrutura social.

\section{Totalidade}

Outro ponto extremamente importante da obra hegeliana a ser destacado é o conceito de totalidade. Qualquer determinação depende, 
para que seja inteligível, daquilo que não é. Ou seja, quando digo "isto" só o entendo pelo fato de tudo mais não ser "isto". Se digo "cadeira”, isso é inteligível pelo fato de que nem tudo é "cadeira”. Como Hegel nos mostra na primeira tríade da Wissenschaft der Logik (Ciência da Lógica), quando digo "tudo é ser" isto é a mesma coisa, no fundo, do que dizer "tudo é nada”. Assim, qualquer determinação pressupõe a totalidade. Em outras palavras, só posso determinar algo em relação ao conjunto de outros elementos que tornam esta determinação inteligível e com sentido. "A totalidade hegeliana supõe [...] um estado de reconciliação” (REPA, 2011, p. 277). Ela [a totalidade], porém, nunca pode ser determinada de modo imediato pois isso significaria que haveria uma totalidade maior ou, simplesmente, significaria que haveria algo para além das suas fronteiras. Ela não seria, nesse caso, totalidade. A totalidade, assim, só pode ser determinada pela dinâmica e pelo conjunto de relações das partes que a constituem. Ela só é visível nos elementos que a compõem. "Dessa maneira, negatividade e totalidade se pressupõem reciprocamente em Hegel. Sem a negatividade, o todo não se põe, mas se o todo não é imanente em cada negação, tampouco a negatividade se efetiva de maneira determinada, isto é, positivamente" (REPA, 2011, p. 275). Adorno reconhece a importância de Hegel por haver colocado esta categoria no centro de sua filosofia.

\footnotetext{
Hegel reconheceu a preeminência do todo com respeito às suas partes, finitas, insuficientes e contraditórias, quando confrontadas com ele. Porém, nem sequer derivou uma metafísica do princípio abstrato da totalidade, nem sequer glorificou o todo enquanto tal em nome da "boa forma": de igual modo que tornou as partes independentes em relação ao todo, como elementos seus, sabia perfeitamente o crítico do Romantismo, que o todo somente (...) se realiza através das partes. Seu todo é, em definitivo, somente a quintessência dos momentos parciais que em cada instante remetem para fora de si mesmos e brotam dissociando-se uns dos outros; não é nada que estivesse para além deles. (ADORNO, 1990, p. 253-254; 2013, p. 74-75).
}

Como bem aponta Fredric Jameson (1997, p.45), “o equívoco reside em concluir que a ênfase filosófica na indispensabilidade dessa categoria consiste na sua celebração." Portanto, essa categoria da dialética mostra que um determinado ente é mais do que aquilo que ele é de modo imediato. Isto é, compreendo de fato um ente quando 
torno claro seu lugar na dinâmica que compõe a totalidade. Já há aqui uma distância crítica por parte de Adorno da associação rápida realizada por Hegel entre as partes e o todo, pois para esse último autor,

[Das Wahre ist] O verdadeiro é o todo. Mas o todo é somente a essência que se implementa através de seu desenvolvimento. Sobre o absoluto, deve-se dizer que é essencialmente resultado; que só no fim é o que é na verdade. Sua natureza consiste justo nisso: em ser algo efetivo, em ser sujeito ou vir-a-ser de si mesmo (HEGEL, 1992, p. 31).

O todo só se afirma na dissolução/subsunção das partes, e somente em sua positivação, por meio das partes e negando-as, ele se põe como verdadeiro. Esclarecida essa distância, que não será abordada aqui por não ser o escopo do texto, exemplificaremos agora a importância que este conceito adquire na filosofia adorniana, no caso de sua análise da obra de arte. Quando o autor da Ästhetische Theorie analisa a situação da arte no mundo contemporâneo, mais do que partir de um conceito abstrato de obra de arte, - isto seria uma determinação da totalidade para além da vida concreta de cada um de seus elementos, isto é, as obras - o que pretende fazer é tornar visível nas obras concretas a dinâmica antagonista que faz algumas delas endossar uma totalidade que aos poucos vai tornando a arte legível e compreensível a partir do critério do mercado (indústria cultural) e outras que tornam esta totalidade compreensível no momento em que se negam a participar dela. Comunicam-se com a totalidade através da não-comunicação. Tornam a regra legível a partir da exceção que inscrevem no seio desta totalidade. Em última análise, portanto, a crítica adorniana não se dirige simplesmente à categoria de totalidade, mas sim, à celebração de uma totalidade para além dos antagonismos que a constituem. Neste elemento, precisamente, a herança hegeliana se mostra plenamente.

Somente se a totalidade, que é uma ilusão socialmente necessária enquanto hipóstase do universal extraído de cada ser humano, for quebrada em sua pretensão de ser absoluta, a consciência social crítica conservará a liberdade de pensar que as coisas podem ser de outro modo um dia. A teoria só pode mover o peso desmedido da necessidade histórica, se essa necessidade histórica é reconhecida como uma aparência 
que se tornou realidade, uma determinação histórica que se tornou, por acaso, metafísica (ADORNO, 1973, p. 317; 2009, p. 268).

\section{Lógica da efetivação (Verwirklichung)}

O terceiro ponto que gostaríamos de ressaltar, para mostrar este profundo enraizamento da obra adorniana na dinâmica da dialética hegeliana, é a lógica da efetivação (Verwirklichung). Como bem o mostra Hegel, as ideias nascem abstratas, inclusive a ideia de razão, e vão se efetivando na história. Por exemplo, a ideia de liberdade nasce abstrata como um ideal regulador na modernidade nascente e vai ganhando "corpo", ou seja, se efetivando até o momento em que deixa de ser um puro em-si abstrato e se torna em-si e para-si, ou seja, se reconhece na efetividade da história. Evidentemente, de acordo com a própria lógica hegeliana, não é preciso aceitar como inevitável ou como consequência de uma teleologia inscrita no conceito de liberdade o modo como este se efetiva nas sociedades liberais. Por isso, para além de uma certa "apologia" dessa efetivação - que fica visível na Filosofia do Direito, por exemplo Adorno pretende continuar mostrando a dinâmica do antagonismo que sobrevive subterraneamente, por mais que a totalidade social insista em esvaziar de sentido qualquer leitura do conceito de liberdade para além do conteúdo concreto que esse conceito adquiriu no Estado liberal (agora em vias de transição para um Estado neoliberal ou pós-liberal). É nesse ponto, especificamente, que Adorno poderá seguir a lógica da obra hegeliana até o ponto em que esta exponha "as contradições da sociedade burguesa." (ADORNO, 1990, p.252). De certo modo, para além do interesse pela dialética como movimento da realidade, o filósofo de Frankfurt está interessado na obra hegeliana pelo fato de esta nos apontar e apresentar a metafísica profunda da época moderna, ou seja, o fato de o autor da Filosofia do Direito nos fazer ver a dinâmica constitutiva desta sociedade. E, portanto, não apenas a sua constituição (seu em-si) mas também a sua justificação e seu discurso legitimador (seu para-si).

Assim, certos conceitos que teriam uma extraordinária força emancipatória (Liberdade, igualdade, direitos humanos, etc.), quando são capturados para dentro da dinâmica concreta das sociedades liberais e têm o seu conteúdo moldado por esta sociedade, perdem seu potencial emancipatório e passam a participar do processo de costura deste véu idológico que encobre a verdadeira dinâmica desta sociedade. Insistir no 
papel antagônico destes conceitos, mostrando que seu conteúdo não precisa apenas consolidar a totalidade que se impõe, mas que pode ser a potência que a explode, continua sendo papel da obra adorniana. Assim, por exemplo, poderíamos pensar a situação atual da luta pelos direitos humanos desde esta leitura de Adorno da filosofia hegeliana. Ou seja, por um lado poderíamos endossar o caráter abstrato e estritamente jurídico destes direitos (o que faria com que coincidissem com o conteúdo abstrato e supostamente universal que as sociedades liberais reservaram a eles), ou então, podemos ver o que excede e explode este conceito ou dinâmica redutora, isto é, mostrar a luta social concreta por direitos no âmbito dos movimentos sociais. Esta perspectiva nada tem de harmonizadora, ao invés disso, expõe as fraturas e contradições de uma realidade que insiste em encobri-las.

\section{Negatividade}

No início da sua grande obra sobre a dialética, Adorno é enfático: "O presente livro gostaria de libertar a dialética de tal natureza afirmativa, sem perder nada em determinação. Uma de suas intenções é o desdobramento de seu título paradoxal.” (ADORNO, 1973, p. 9; 2009, p.7). Esta afirmação contém alguns elementos que podem ser explorados para compreender o exato alcance e determinação deste conceito de negatividade tanto na filosofia hegeliana como na obra do filósofo de Frankfurt. Inicialmente, chama atenção o fato de Adorno insistir no caráter paradoxal do título Dialética Negativa. Com isso, o autor já aponta para o núcleo daquilo que gostaríamos de tematizar neste momento de nosso estudo, isto é, a negatividade. O título é paradoxal exatamente pelo fato de a dialética conter em si, essencialmente, o elemento negativo. Dialética negativa, assim, é uma formulação que corre um imenso risco de se tornar redundante. Esta consciência do caráter paradoxal do título mostra, perfeitamente, a consciência que seu autor possui da importância da negatividade na filosofia hegeliana. Antes de insistir mais na análise da programática frase que acabamos de citar, faz-se necessária, portanto, uma consideração mais próxima sobre esta negatividade a partir da especificidade da filosofia hegeliana.

Na obra de Hegel, como sabemos, o conceito de mediação é absolutamente central. Tudo o que é remete a uma totalidade no interior 
da qual cada elemento determinado vai afirmando sua identidade. No entanto, a identidade, a partir desta concepção dialética, não é algo estático. A identidade somente aparece no horizonte de um conjunto de relações profundamente marcadas pela negatividade. O conceito de negatividade e o conceito de totalidade, assim, estão fundamentalmente relacionados. Se não houvesse uma negatividade constitutiva de cada um dos elementos que compõe o todo, este poderia ser representado por uma figura estática. O todo hegeliano, como já foi apontado em nosso estudo, não é nada disso. A totalidade é a tensão entre afirmação e negação que se manifesta em cada elemento particular. O todo é a face negativa de cada uma das partes. É a abertura fundamental que permite com que cada elemento seja mais do que aquilo que é, ou seja, esteja aberto ao devir. Como bem afirma Repa (2011, p. 275), "o todo, o absoluto, se desenvolve por meio da negação determinada de suas formas particulares e finitas, até chegar o momento em que todas as particularidades se tornam voláteis. Se a negatividade não fosse uma forma de positividade, o desenvolvimento do todo seria impensável”. Isto é, toda identidade está sempre sujeita à fragmentação exatamente pelo fato de estar aberta a um jogo relacional no interior da totalidade. Assim, cada determinação é também uma negação. A filosofia dialética pretende ser exatamente a teoria capaz de captar esse constante movimento, cujo motor é a negatividade.

É no reconhecimento da absoluta centralidade desta categoria de negatividade para a dialética, que Adorno insiste na formulação dialética negativa. Como, desse modo, escapar do caráter redundante deste conceito? Inicialmente, a negatividade coincide com aquele movimento que impulsiona o pensamento dialético. Ou seja, é a negação de um pensamento abstrato que, desde uma perspectiva subjetiva, simplesmente descreve a realidade. Esse pensamento abstrato é negado pela necessidade teórica de acompanhar o próprio desdobramento concreto do real, de modo imanente. Esta perspectiva, onde o próprio real é pensamento e onde o pensamento é efetivo, portanto, é o sentido mais elementar desta negatividade adorniana. Além disso, a negatividade se constitui como a mola propulsora de um conjunto de relações no interior de uma totalidade. É no jogo relacional que algo pode se determinar. No entanto, se o conceito significasse apenas isso, Adorno não estaria trazendo nenhuma novidade 
para a teoria dialética e, dessa maneira, o adjetivo negativa estaria muito pouco justificado. A negatividade contém, portanto, ainda outro sentido.

A dialética hegeliana mostra como sujeito e objeto estão mutuamente mediados no interior da totalidade e, dessa forma, completamente integrados numa dinâmica imanente que o autor da Fenomenologia do Espírito expõe como sendo a dinâmica do conceito. Está dinâmica é tanto a dinâmica da realidade como, também, sua autocompreensão. No entanto, esta lógica efetiva que expõe o movimento do real e sua compreensão, corre o risco de tornar-se uma filosofia da identidade. Ou seja, para que uma determinada lógica se torne visível e dominante, muitas outras formas e identidades são negadas. Neste momento, esta filosofia já não terá mais como foco a totalidade como tensão entre identidade e não identidade, que se manifesta em cada elemento particular. Ao invés disso, passará a descrever apenas a lógica da realidade como oniabrangente a ponto de integrar todos os elementos. Isto nos levaria a "reconhecer a razão como rosa na cruz do sofrimento presente.” (HEGEL, 1997, p.37). Vejamos como Adorno (1990, p. 355; 2013, p. 217) analisa este aspecto:

Com ele (HEGEL) a filosofia se converte em um contemplar e descrever o movimento do conceito, a Fenomenologia do Espírito esboça já, virtualmente, sua historiografia. Hegel pretende algo como modelar, com toda pressa, sua exposição de acordo com ela, filosofar como se estivesse escrevendo história e conseguisse, com toda força, graças ao modo de pensar, a unidade do sistemático e do histórico na dialética. Desde esta perspectiva, o que claramente falta à filosofia hegeliana seria a consequência da dimensão histórica refletida sobre si mesma: a exposição oculta a pista de um elemento empírico, incomensurável no conceito.

A negatividade adorniana, desse modo, é algo que acompanha o elemento negativo próprio da dialética e, no limite, o extrapola. O negativo, neste sentido mais radical, é algo que resiste a qualquer integração em uma perspectiva de sistema. O desenvolvimento imanente de certa lógica que se torna visível na história não pode ser aceito simplesmente como parâmetro de justificação filosófica. A história não será aquela que julga a verdade. Este é o risco do historicismo. A negatividade adorniana é aquele impulso que permite, a partir dos elementos que a dinâmica do conceito não consegue integrar, criticar esta dinâmica. Não simplesmente aceitar o curso da história tal como se apresenta pelo fato de ser o resultado de um 
processo imanente de desenvolvimento. O que a negatividade adorniana pretende tornar possível é uma abertura para fugir do jugo da história e da consequente legitimação do presente. Neste sentido, as seguintes palavras de Adorno (apud: BUCK-MORSS, 1981, p.108) são bastante precisas: "a história está na verdade, a verdade não está na história".

\section{${ }^{*}$ Considerações finais}

Enfim, a pretensão dessa abordagem foi apontar para o cuidado necessário na leitura de Hegel, afim de não cairmos na tentação de repetir chavões anti-hegelianos que surgem de um parcial conhecimento de sua obra. Este cuidado e esta seriedade perpassam, de acordo com o nosso modo de ver as coisas, a obra de Theodor W. Adorno. Alguém poderia perguntar por que um dos tópicos desta análise não foi a dialética propriamente. Neste caso, nossa resposta seria a de que é exatamente através deste conjunto de categorias que foram apresentadas ao longo do trabalho, que se pode vislumbrar o sentido próprio da dialética em cada um dos autores.

A insistência de Adorno, nas diferentes etapas de sua obra, em compreender e confrontar a filosofia hegeliana, não é fruto de um capricho pessoal. O filósofo de Frankfurt tinha a exata dimensão da importância da dialética hegeliana na constituição de uma teoria crítica da sociedade. O caráter não dogmático desta obra é, verdadeiramente, um laboratório para a construção de uma análise filosófica da dinâmica social, bem como, para a construção de uma teoria que já não se afaste de maneira abstrata da realidade concreta. Além disso, se lida com o cuidado necessário, conduz a questionamentos que desde seus próprios termos leva ao questionamento da articulação, aparentemente necessária, da dialética e do idealismo.

\section{Referências}

ADORNO, Theodor. Negative Dialektik. In: Gesammelten Schriften. Band 6, Frankfurt am Main: Suhrkamp Verlag, 1973.

. Drei Studien zu Hegel. In: Gesammelte Schriften. Band 5. Frankfurt am Main: Suhrkamp Verlag, 1990.

. Die revidierte Psychoanalyse. Gesammelte Schriften. Band 8. Frankfurt am Main: Suhrkamp Verlag, 1995. 
. Dialética Negativa. Trad. Marco Antonio Casanova. Rio de Janeiro: Jorge Zahar, 2009 .

. Três estudos sobre Hegel. Trad. Ulisses Razzante Vaccari. São Paulo: Ed. UNESP, 2013 .

BENJAMIN, W. Magia e Técnica, arte e política: ensaios sobre literatura e história da cultura. In: Obras Escolhidas. Vol. I. Trad: Paulo Sérgio Rouanet. 7.ed. São Paulo: Brasiliense, 1994 .

BUCK-MORSS, Susan. Origen de la Dialectica Negativa: Theodor W. Adorno, Walter Benjamin y el Instituto de Frankfurt. Trad. Nora Rabotnikof Maskivker. Cerro del Agua: Siglo Veintiuno Editores, 1981.

FLECK, Amaro. Da crítica imanente à crítica do sofrimento: a justificação normativa na obra tardia de Adorno. In: ethic@, Florianópolis, v.15, nº 1, p. 65-84, jul. 2016.

HEGEL, G.W.F. Fenomenologia do Espírito. Parte I. Trad. Paulo Meneses; apresentação Henrique Vaz. 2.ed. Petrópolis, Vozes, 1992.

. Linhas fundamentais da filosofia do direito, ou, Direito natural e ciência do estado em compêndio. Trad. Paulo Meneses, Agemir Bavaresco, Alfredo Moraes, Danilo Vaz-Curado R. M. Costa, Greice Ane Barbieri e Paulo Roberto Konzen. São Leopoldo, RS: Ed. UNISINOS, 2010.

JAMESON, Fredric. O marxismo tardio: Adorno, ou a persistência da dialética. Trad. Luiz Paulo Rouanet. São Paulo: Fundação Editora da UNESP: Editora Boitempo, 1997.

PERIUS, Oneide. Esclarecimento e Dialética Negativa: sobre a negatividade do conceito em Theodor W. Adorno. Passo Fundo: Editora IFIBE, 2008.

REPA, Luiz. Totalidade e negatividade: a crítica de Adorno à dialética hegeliana. In: CADERNO CRH, Salvador, v. 24, n. 62, p. 273-284, Maio/Ago. 2011.

SAFATLE, Vladimir. Materialismo e dialéticas sem Aufhebung: Adorno leitor de Marx: Marx leitor de Hegel. In: Veritas, Porto Alegre, v. 62, nº 1, jan,-abr. 2017, p. 226-256.

\section{Endereço Postal:}

Universidade Federal do Tocantins Câmpus de Palmas

Avenida NS 15, Quadra 109, Palmas - TO, Brasil

Data de recebimento: 25/05/2018

Data de aceite: 17/o9/2018 